\title{
Can Human Capital Theory Explain Why Nurses Are So Poonly Paid?
}

\author{
by \\ Margaret J. N owak \& Alison C. Preston \\ Women's Economic Policy Analysis Unit \\ Curtin University of Technology
}

Discussion Paper Series 00/ 2

A pril 2000

Women's Economic Policy Analysis Unit (WEPAU), c/ o Department of Economics, Curtin Business School, Curtin University of Technology,

GPO Box U 1987, Perth 6845. 


\title{
Can Human Capital Theory Explain Why Nurses Are So Poorly Paid?
}

\author{
Margaret J. Nowak \& Alison C. Preston*
}

\begin{abstract}
This paper uses Australian Census data to examine the earnings of female professionals. Comparisons are made between Registered Nurses (RNs), Teachers, Social Professionals, Health Professionals and Business Professionals. Wage decompositions show that RNs earn significantly less than other female Professionals and that the observed differentials cannot be explained by differences in human capital endowments. The evidence presented is strongly suggestive of monopsonist or oligopsonist power in the setting of nurse wages - with a manifestation being persistent labour market disequilibrium. Changing the relative reward structure for nurses may help address the on-going nursing 'shortage' in Australia, although further research in this area is called for.
\end{abstract}

\section{INTRODUCTION}

The continuing nursing "shortage", exacerbated by a fall in demand for graduate nursing programs and a large attrition of junior registered nurses (RNs) shortly after graduating is of growing concern in Australia. An aging population and a projected mismatch in the demand for, and supply of, nurses suggests a serious problem is looming in the area of health care delivery (Nowak, 2000). In responding to these concerns Health Departments throughout Australia have commissioned a series of research papers examining factors associated with nurse labour supply (e.g. BIZTRAC 1998; Lawler, Ahern, Stanley and West 1997; Hearn and Sheahan 1998).

A dominant theme emerging from this research is a perception that nurses are underpaid. High School students in the Hearn and Sheahan study, for example, commented that nurses "... are not really paid for what they do, they work their butts off for nothing" (ibid, p.16). In the BIZTRAC study of junior RNs pay emerged as a significant factor in the decision to stay or leave the profession. On a scale of 1 to 7 (with $1=$ strong disagreement and $7=$ strong agreement) the mean responses to the following pay questions were as follows (the standard deviations are reported in parentheses):

\footnotetext{
* We are grateful to Elisa Birch for research assistance.
} 
- I think higher pay would attract more people into nursing: $\bar{x}=6.35$ (1.19)

- I don't get paid enough for my responsibilities: $\bar{x}=6.31$ (1.26)

Such responses engender an obvious question, "Are nurses underpaid?" Using the human capital model as a framework for analysis the remainder of this paper examines this empirical question. Comparisons are made between female Registered Nurses (RNs) and other female professionals, specifically Teachers, Social Professionals, Business Professionals and Health Diagnosis and Treatment Practitioners

The article is set out as follows. Section II presents a brief overview of the theoretical model. Section III describes the data used in the empirical analysis. Section IV presents and discusses the results. Section V contains a summary and conclusion.

\section{HUMAN CAPITAL AND THE DISTRIBUTION OF EARNINGS}

In contemporary economic literature a dominant framework for the study of wage determination is the human capital model. The model postulates that individuals investing in the accumulation of human capital (e.g. education and training) recoup the costs of their investment (e.g. foregone earnings and tuition costs) in the form of higher lifetime earnings. The model further suggests that women who plan to engage in non-continuous workforce attachment (e.g., because of their anticipated family responsibilities) will choose jobs where the returns to work experience will be lower, but the penalties for labour force interruptions smaller. Thus, all else equal, women in these sorts of jobs should expect to have higher starting salaries but flatter profiles and smaller penalties associated with experience interruptions (Mincer and Polacheck 1974; Polachek 1975; Polachek 1981). The model may be stated algebraically as follows:

$$
\ln \hat{Y}_{i}=\hat{\beta}_{0}+V_{i} \hat{\beta}_{i}
$$

where $\ln Y$ denotes the natural logarithm of weekly earnings, $f$ denotes females, $V$ is a vector of characteristics known to affect wages (e.g. qualifications, labour market experience, demographic characteristics, industry and occupation of employment); and $\hat{\beta}$ is a vector of estimated slope coefficients associated with these characteristics. The latter provides a measure of the market (employer) valuation of the characteristics controlled for in the wage equation. The typical earnings profile sees wages rise at a decreasing rate, reaching a peak or plateau later in the working life. Earnings profiles differ among individuals; better educated persons typically exhibit higher and steeper earning profiles.

There are two ways in which the human capital framework may be used to study the relative earnings of RNs vis a vis other female professionals. The simplest is to include a set of occupational dummy variables in a pooled wage equation. The level of wage advantage/disadvantage may be measured by the coefficients of the occupational dummies. A more sophisticated approach involves the estimation of separate wage equations for each comparator groups. The observed differences in average wages in each group are then decomposed into explained and unexplained components following the Blinder (1973) and Oaxaca (1973) decomposition procedure. This technique provides insight into the determinants of the difference, and may be summarised as follows. 
$\overline{\ln Y_{N}}-\overline{\ln Y_{J}}=\left(\bar{V}_{N}-\bar{V}_{J}\right) \hat{\beta}_{N}+\bar{V}_{J}\left(\hat{\beta}_{N}-\hat{\beta}_{J}\right)+\left(\hat{\beta}_{0 N}-\hat{\beta}_{0 J}\right)$

where: $\mathrm{N}$ denotes RNs and $\mathrm{J}$ denotes the comparator occupational group; $\bar{V}$ is a vector of the means of the independent variables and $\hat{\beta}$ is a vector of estimated slope coefficients showing how employers value the various characteristics. In this decomposition the nursing pay structure is assumed to be the 'non-discriminatory' norm.

The first term of the decomposition calculates the portion of the occupational earnings gap attributable to differences in individual characteristics of RNs and females in other professional groups. This component may be labelled the explained portion (or skill differential). The second term calculates occupational differences in the valuation of these skill characteristics. This, together with the third term, measure the adjusted relative earnings treatment advantage/disadvantage of RNs vis a vis the comparator group.

\section{DATA}

The data for the study are drawn from the 1991 Census one per cent Household Sample Files (HSFs). In keeping with similar studies in this area the sample is restricted to full-time wage and salary earners aged between 16 and 64 years. ${ }^{2}$ We further restrict our sample to female professionals and make comparisons across RNs, Teachers, Social Professionals (Social Workers, Counsellors, Lawyers and Ministers of Religion), Business Professionals (Accountants, Public Relations Officer, Personnel Specialists, Computing Professionals and other business professionals) and Health Diagnosis and Treatment Practitioners (General and Specialist Medical, Pharmacists, Occupational Therapists, Optometrists, Physiotherapists, Speech Pathologists, Chiropractors and Osteopaths, Podiatrists, Radiographers, Veterinarians and other health diagnosis and treatment practitioners). Restricting the sample in this way resulted a sample size of 2308 females employed full-time in professional occupations. (Appendix A provides details on the data and variables used).

The dependent variable in all cases is the natural logarithm of weekly earnings (lnY). This variable picks up the weekly earnings from all sources (including overtime, allowances, interest etc.). The income data are grouped, thus the midpoints of each interval are used to estimate weekly earnings. Following Chiswick and Miller (1995) the open-ended upper limit is given a value of 1.5 times the lower threshold level.

One weakness with the Census data (a weakness shared by many other data sets) is the lack of information on actual labour market experience. Following convention 'potential' labour market experience is defined here as age minus years of schooling minus 5 (assumed age when school commenced). It is generally acknowledged that this 'potential' measure is a poor proxy for female labour market experience - on account of their intermitted labour market

\footnotetext{
1 In Australia a population Census is conducted every five years. The next one will take place in 2001. A public release one per cent unit record household sample file (HSF) from the 1996 Census is available for analysis purposes. We are, however, unable to use the 1996 Census data here due to the aggregation of some occupational groups. Nurses, for example, are grouped in with Health Professionals. Teachers are grouped in with Educational Professionals.

$2 \quad$ Full-timers are defined as those working 35 or more hours per week in their main job. Our rational for restricting the sample to full-time wage and salary earners is to overcome some of the estimation difficulties associated with measuring the labour market experience of persons employed part-time.
} 
activity. A number of different techniques may be employed to try to overcome the limitations of not having data on actual labour force experience. Some studies employ the potential measure and augment the regression equation with additional variables such as marital status and children to capture spells of absence from the workforce (eg. Gregory and Daly 1990). Others impute actual measures of experience from other equations (e.g Miller and Volker 1993). In the absence of data on actual work history any measure of experience will, however, be plagued by statistical biases (Blinder 1976). Accordingly, this paper uses the simple 'potential' measure in marital status/children augmented wage equation. The estimation technique is ordinary least squares (OLS).

\section{RESULTS AND DISCUSSION}

$\underline{\text { Results }}$

Table I below presents the results from a pooled wage equation (i.e. using the total sample of 2308 professional females). The estimates show that earnings rise with education and that the experience-earning profiles have the conventional inverted U-shape. For example, females with a diploma earn 20.6 per cent more than the reference group (those in possession of a skilled certificate, associate diploma qualification or less). ${ }^{-6}$ The corresponding earnings premium for degree holders was 29 per cent - which is significantly higher $(t=2.452)$. An additional year of labour market experience raises their earnings by 1.8 per cent (evaluated at 10 years of labour market experience). Working 41 or more hours per week is associated with significantly more earnings, ceteris paribus. Birthplace is not a significant predictor of earnings. Marital status and the presence of dependant children are, however, important determinants. Female professionals who are married earn 5.5 per cent more than their never married counterparts. The presence of dependant children is associated with significantly lower earnings - with the disadvantage equal to 9.7 per cent. Working in the government sector attracts a premium of 3.2 per cent. Those employed in the metropolitan area also have a slight earnings advantage, equal to 2.5 per cent.

Turning to occupation the results suggest that, relative to RNs, there is no significant difference in the earnings of School Teachers and Social Professionals, ceteris paribus. Business Professionals and Health Professionals earn significantly more than RNs, with the difference equal to 8.5 and 22 per cent, respectively.

\footnotetext{
3 The Breusch-Pagan (BP) test is used to detect whether or not heteroskedasticity is present and, where detected, White's (1980) technique used to correct the standard errors.

4 In semi-logarithmic equations the coefficients of dummy variables which are small in value may be interpreted as the percentage effects on the dependent variable, relative to the omitted category (Halvorsen and Palmquist 1980).
} 


\section{Table I}

Determinants of the Earnings of Female, Professional, Wage and Salary Earners, Employed Full-Time, 1991.

\begin{tabular}{|c|c|c|c|c|}
\hline & $\hat{\beta}$ & $\begin{array}{l}\text { Absolute } \\
\text { t-stat. }\end{array}$ & & Mean \\
\hline Constant & 5.829 & 165.408 & $*$ & \\
\hline Highest Education Level & & & & \\
\hline Undergraduate Diploma & 0.206 & 7.963 & $*$ & 0.346 \\
\hline Degree or Higher & 0.292 & 12.344 & $*$ & 0.477 \\
\hline Labour Force Experience & & & & \\
\hline Experience & 0.031 & 11.341 & $*$ & 15.511 \\
\hline$($ Experience squared)/100 & -0.065 & 8.921 & $*$ & 3.453 \\
\hline Working hours & & & & \\
\hline Works 41+ hours per week. & 0.063 & 4.053 & $*$ & 0.270 \\
\hline Demographics & & & & \\
\hline Born English-Speaking Country & -0.003 & 0.158 & & 0.123 \\
\hline Born non English-Speaking Country & 0.004 & 0.194 & & 0.110 \\
\hline Married & 0.055 & 3.667 & $*$ & 0.540 \\
\hline Widowed, Separated, Divorced & 0.048 & 2.058 & $*$ & 0.115 \\
\hline Has a Dependant Child & -0.097 & 6.090 & * & 0.336 \\
\hline Sector of Employment & & & & \\
\hline Government & 0.032 & 2.418 & $*$ & 0.609 \\
\hline Area of employment & & & & \\
\hline Metropolitan & 0.029 & 2.289 & $*$ & 0.694 \\
\hline Occupation & & & & \\
\hline School Teacher & 0.000 & 0.015 & & 0.390 \\
\hline Social Professional & 0.043 & 1.039 & & 0.056 \\
\hline Business Professional & 0.085 & 3.330 & $*$ & 0.202 \\
\hline $\begin{array}{l}\text { Health Diagnostician/Treatment } \\
\text { Practitioner }\end{array}$ & 0.221 & 6.639 & $*$ & 0.081 \\
\hline Dependent Variable: $\ln (\mathrm{Y})$ & 6.398 & & & \\
\hline Adjusted $\mathrm{R}^{2}$ & 0.205 & & & \\
\hline Breusch-Pagan(16) & 639.499 & & & \\
\hline Sample Size & 2308 & & & \\
\hline
\end{tabular}

Notes: * indicates significance at the 5 per cent level or better. 


\begin{tabular}{|c|c|c|c|c|c|c|c|c|c|c|c|c|c|c|c|}
\hline \multirow[b]{2}{*}{ Variable } & \multicolumn{3}{|c|}{$\mathbf{R N}$} & \multicolumn{3}{|c|}{ School Teacher } & \multicolumn{3}{|c|}{ Social Professional } & \multicolumn{3}{|c|}{ Health Professional } & \multicolumn{3}{|c|}{ Business Professional } \\
\hline & $\hat{\beta}$ & t-stat & mean & $\hat{\beta}$ & t-stat & mean & $\hat{\beta}$ & t-stat & mean & $\hat{\beta}$ & t-stat & mean & $\hat{\beta}$ & t-stat & mean \\
\hline constant & 5.826 & 112.809 & & 5.950 & 148.208 & & 5.284 & 26.704 & & 5.747 & 34.782 & & 5.895 & 104.628 & \\
\hline diploma & 0.378 & 8.347 & 0.74 & 0.057 & 1.563 & 0.31 & 0.520 & 4.374 & 0.03 & 0.315 & 2.787 & 0.16 & 0.060 & 0.579 & 0.05 \\
\hline degree & 0.402 & 8.052 & 0.17 & 0.176 & 5.422 & 0.61 & 0.693 & 5.904 & 0.85 & 0.481 & 4.349 & 0.72 & 0.244 & 6.662 & 0.42 \\
\hline & 0.012 & 3.277 & 16.38 & 0.029 & 10.650 & 16.13 & 0.052 & 2.846 & 17.61 & 0.061 & 5.768 & 13.14 & 0.041 & 6.314 & 13.54 \\
\hline $\exp ^{2} / 100$ & -0.022 & 2.433 & 3.90 & -0.055 & 7.507 & 3.61 & -0.116 & 2.576 & 4.07 & -0.139 & 5.149 & 2.63 & -0.094 & 5.631 & 2.71 \\
\hline otime & 0.032 & 0.736 & 0.09 & 0.036 & 2.521 & 0.34 & 0.005 & 0.057 & 0.40 & 0.188 & 2.869 & 0.35 & 0.080 & 2.108 & 0.31 \\
\hline$e s b$ & 0.021 & 0.718 & 0.17 & -0.031 & 1.254 & 0.08 & 0.111 & 1.065 & 0.11 & -0.153 & 1.316 & 0.15 & 0.058 & 1.090 & 0.13 \\
\hline$n e s b$ & 0.037 & 1.312 & 0.14 & -0.073 & 2.113 & 0.07 & 0.107 & 0.868 & 0.08 & 0.014 & 0.140 & 0.11 & 0.062 & 1.365 & 0.15 \\
\hline married & 0.043 & 1.627 & 0.53 & 0.052 & 2.797 & 0.60 & 0.143 & 1.530 & 0.50 & 0.106 & 1.690 & 0.51 & 0.026 & 0.734 & 0.46 \\
\hline wsd & 0.084 & 2.277 & 0.13 & 0.074 & 2.995 & 0.11 & -0.099 & 0.818 & 0.18 & 0.208 & 1.566 & 0.06 & -0.005 & 0.080 & 0.11 \\
\hline child & -0.057 & 1.995 & 0.32 & -0.077 & 4.988 & 0.41 & -0.105 & 1.189 & 0.36 & -0.197 & 2.127 & 0.27 & -0.163 & 3.721 & 0.23 \\
\hline govt & 0.026 & 1.083 & 0.71 & 0.049 & 3.083 & 0.72 & -0.042 & 0.537 & 0.49 & -0.056 & 0.858 & 0.54 & 0.045 & 1.433 & 0.33 \\
\hline metro & 0.005 & 0.187 & 0.67 & 0.025 & 1.672 & 0.63 & 0.176 & 2.554 & 0.73 & -0.007 & 0.094 & 0.78 & 0.034 & 1.030 & 0.81 \\
\hline $\ln (Y)$ & 6.344 & & & 6.403 & & & 6.477 & & & 6.599 & & & 6.357 & & \\
\hline Adj $R^{2}$ & 0.175 & & & 0.250 & & & 0.303 & & & 0.240 & & & 0.152 & & \\
\hline $\mathrm{BP}(12)$ & 63.495 & & & 198.772 & & & 38.216 & & & 64.859 & & & 64.530 & & \\
\hline $\mathrm{N}$ & 624 & & & 901 & & & 129 & & & 188 & & & 466 & & \\
\hline
\end{tabular}

Notes: Table II reports absolute t-statistics. 
Table II reports the results by occupational group. For all groups education and experience emerge as a significant determinant - although differences are apparent. Evaluated at 10 years, the estimates show that an additional_year of labour market experience would raise the earnings of RNs by 0.8 percentage points. Corresponding estimates for School Teachers, Social Professionals, Health Professionals and Business Professionals are: 1.8, 2.9, 3.3 and 2.2 percentage points, respectively. Thus it is apparent that, when compared to females in other professions, the experience-earning profile of nurses is flat. Figure I demonstrates this point graphically. The occupational experience-earnings profiles that are shown there have been calculated from the estimates contained in Table II. The hypothetical starting wage of $\$ 14$ per hour corresponds, closely, to the average hourly wage in the nursing sample studied here.

\section{Figure I: Hypothetical Experience-Earning Profiles}

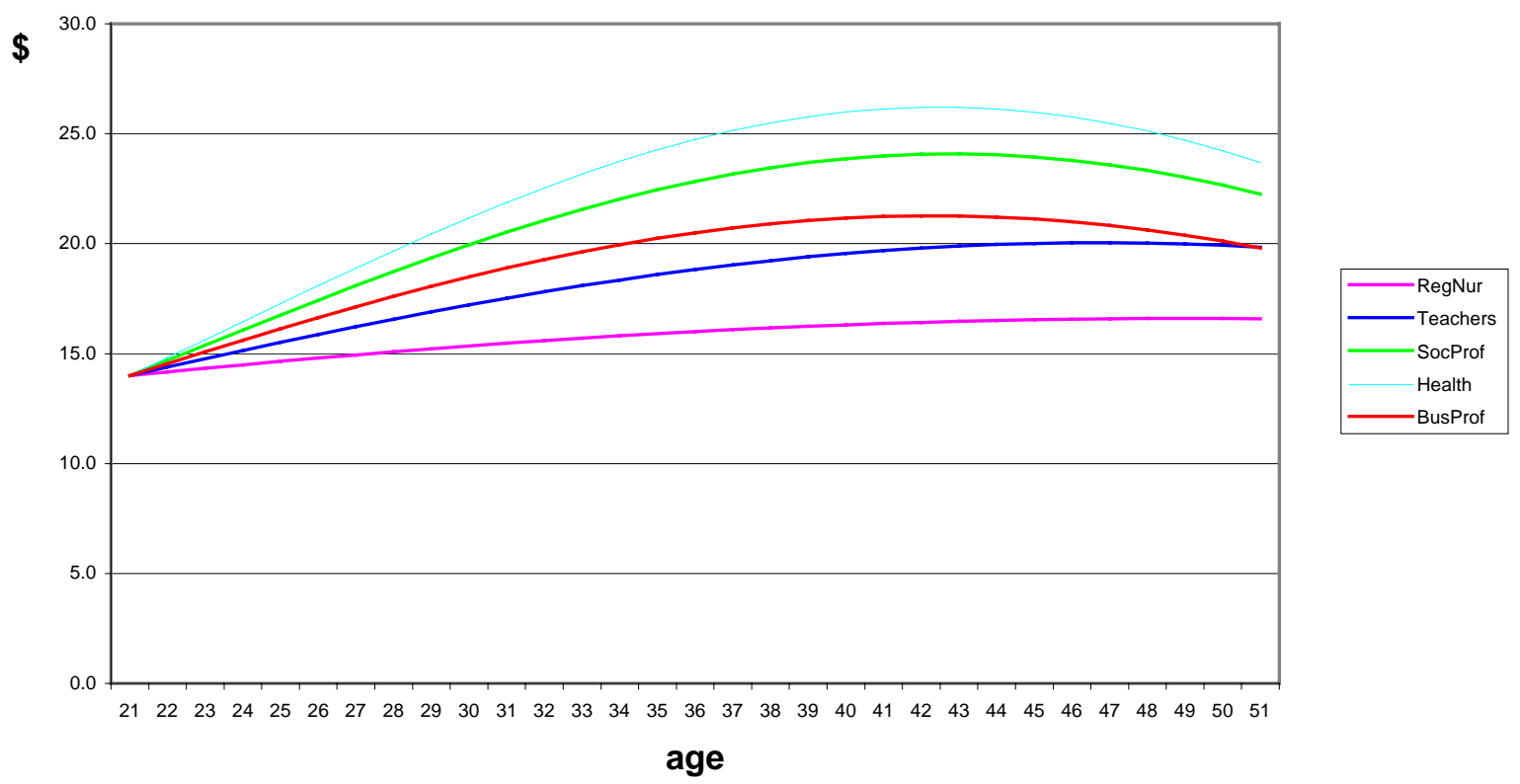

Source: Table II.

Other differences across the groups emerge with respect to overtime work and the presence of dependant children. Teachers, Health Professionals and Business Professionals receive significantly higher earnings if they work long hours (41 or more per week). The coefficients on the otime variable indicate that Teachers working long hours earn 3.6 per cent more than their counterparts working 35-40 hours per week. The corresponding earnings advantage for Health Professionals and Business Professionals is 18.8 and 8 per cent, respectively. In the case of RNs and Social Professionals long working hours is not associated with significantly higher earnings.

Turning to children, the results show that females in all groups - except Social Professionals - suffer a significant earnings loss if they have dependant children. In the case of Health

$5 \quad$ Hirsch and Schumacher (1995) estimate a standard log wage equation for a sample of registered nurses $(n=24,345)$ in the US and similarly find that an additional year of labour market experience (evaluated at 10 years) raises $\mathrm{RN}$ earnings by 0.7 per cent. 
Professionals the earnings disadvantage is equal to 19.7 per cent. Business Professionals with children similarly experience a large earnings gap, equal to 16.3 per cent. Within the nursing and teaching professions the earnings differential is still significant, although the degree of disadvantage lower. RNs with children receive 5.7 per cent less than nurses without children. Teachers with children earn 7.7 per cent less than female teachers without children.

Overall it is apparent that there are some significant differences in the determinants of the earnings of nurses and other female professionals. Such differences are reflected in a gap in the relative earnings of RNs vis a vis other female professionals. In Table III below we use the regression results of Table II to decompose the earnings differentials for RNs and other female professionals into explained and unexplained components.

\section{Table III}

Decomposing the Earnings Differentials of RNs and Other Female Professionals

\begin{tabular}{|l|c|ccccccc|c|}
\hline \multirow{1}{*}{$\begin{array}{c}\text { RN } \\
\text { relative to: }\end{array}$} & Raw & \multicolumn{7}{|c|}{ Explained Components } & Adjusted \\
\cline { 3 - 8 } & Gap & Education & Experience & overtime & demog & govt & Total & Gap \\
\hline & \multicolumn{8}{|c|}{ percentage points } \\
\hline Teacher & -5.9 & -1.3 & -0.3 & -0.8 & 0.9 & 0.0 & -1.5 & -4.4 \\
Social P. & -13.4 & -0.4 & -1.2 & -1.0 & 0.3 & 0.6 & -1.7 & -11.7 \\
Health P. & -25.5 & 0.1 & 1.2 & -0.8 & 0.6 & 0.4 & 1.6 & -27.1 \\
Business P. & -1.3 & 16.2 & 0.9 & -0.7 & 0.0 & 1.0 & 17.4 & -18.7 \\
\hline
\end{tabular}

Source: Table II.

The first column of Table III shows that there is a gap in the average earnings of RNs and Teachers equal to 5.9 percentage points (i.e. Teachers earn, on average, 5.9 per cent more than Nurses). The average earnings of Social Professionals is 13.4 per cent more than that of RNs. Corresponding estimates for Health Professionals and Business Professionals are 25.5 and 1.3 per cent, respectively. These results are, however, raw estimates. That is, they have not been corrected for differences in the characteristics of RNs and females in other professional groups. Any analysis of these gaps must first attempt to control for differences in the characteristics of the groups, that is, control for factors that may explain the higher relative earnings.

On doing this we find that it is possible to 'explain' a portion of the Teacher and Social Professional gaps. In the case of Teachers the results show that differences in their educational attainments accounts for 1.3 percentage points of the 5.9 percentage point gap. Overall differences in the characteristics of Teachers and Nurses explain 1.5 percentage points of the gap - resulting in an adjusted earnings gap of 4.4 percentage points.

In the case of Social Professionals differences in levels of labour force experience account for 1.2 percentage points of the 13.4 percentage point gap. After adjusting for other explained factors the earnings gap falls from 13.4 per cent to 11.7 per cent.

Turning to Health and Business professionals, the results show that after adjustments have been made for the differences in their characteristics vis a vis nurses, the adjusted earnings

\footnotetext{
$6 \quad$ See Section II for a discussion of this methodology. have 16.4

The results in Table II show that, on average, Social Professionals have 17.6 years of experience; RNs
} 
gap actually widens. Differences in the experience levels of Health Professionals (average of 13.1 years compared to 16.4 years for nurses) accounts for the most of the extra growth. Amongst Business Professionals differences in educational qualifications contributes an extra 16.2 percentage points to the gap. Results in Table 2 show that 91.5 per cent of Nurses and only 47.2 per cent of Business Professionals hold an undergraduate diploma or higher. Taking these differences into account results in an adjusted earnings gap of 18.7 per cent.

It should be noted that the above estimates are likely to underestimate the extent of the RNfemale Professional earnings gap. The available data do not allow us to examine earnings associated with a standard working week, nor do the allow us to control for any compensatory wage differential which nurses may be in receipt of. Shift work is an important feature of nursing. Schumacher and Hirsch (1997) show that of a sample of 1242 RNs, almost half work day shifts. The remainder work evening, night, rotating/split or other combinations of shifts. In their study evening shift nurses earned, on average, five per cent more than day shift nurses. Those on night shift had an earnings premium equal to 12.7 per cent. Schumacher and Hirsch also observed a significant difference in the earnings of hospital employed RNs and RNs employed elsewhere. They attribute this difference to compensatory wages associated with undesirable attributes associated with hospital employment (such as stress, job hazards etc.). The differentials observed above are inclusive of any compensatory wage premia that nurses may be in receipt of.

\section{Discussion}

The results in the previous section show that perceptions that nursing is a low paid job are not unfounded. Relative to females in other professions such as Health and Business, RNs are significantly disadvantaged. In 1991 the adjusted RN-Health Professional earnings gap was equal to 27.1 per cent and the adjusted RN-Business Professional earnings gap equal to 18.7 per cent. Overall it is apparent that human capital theory is not able to account for a large component of the earnings differential between female RNs and other female professionals.

What else might explain the gap? A number of possible explanations may be advanced, including the historical undervaluation of women's work, occupational crowding, sexsegregation, the characteristics of the labour market for nursing personnel and custom and tradition.

Socialist-feminists argue that "... male power and biases in the culture lead to a devaluation ... of work done by women, and of the skills and activities typically performed by women." (England 1992, p.105). Jobs which require typical female skills (eg. nurturing skills, verbal skills, finger dexterity) are all undervalued relative to 'male' jobs (emphasising physical strength, mathematical skills, supervisory or managerial power) (ibid.). Males employed in highly feminised occupations will, therefore, suffer an earnings disadvantage as well. ${ }^{2}$

\footnotetext{
$8 \quad$ It should be noted that the dependent variable does not measure ordinary time earnings - i.e. earnings associated with standard working hours (e.g. Monday to Friday, 9 to 5.30). Rather, it measures total earnings. Nurses employed full-time do typically work shifts. Indeed shift-work during unsociable hours is frequently used by nurses as a way of boosting their earnings. The measure used here is, thus, likely to overstate the actual hourly earnings of nurses. In this sense the earnings gaps of nurses vis a vis females in other professions are likely to be underestimated.

$9 \quad$ Recent research by Wooden (1999, p.162) shows that, across industries men working in almost totally female-dominated occupations earn 18.4 per cent less than men with otherwise identical characteristics but who are employed in almost totally male dominated occupations.
} 
In Australia a historical dependence on institutionally determined wages and the use of principles such as 'needs' have also served to disadvantage women in traditional female jobs. Prior to ratification of the principle of Equal Pay for Equal Work (EPEW) in 1968 claims for equal pay in Australia were often dismissed on the grounds that "... it was socially preferable to provide a higher wage for the male because of his social obligations to fiancée, wife and family" (Basic Wage Inquiry, 1949-50; 68 CAR 698). In other words, the 'needs' of females were less. Since the adoption of the principle of EPEW and a subsequent principle of Equal Pay for Work of Equal Value (EPWEV) in 1972 attempt has been made to re-value the work of nursing. In 1985 the Australian Council of Trade Unions (ACTU) and the Council of Action for Equal Pay (CAEP) used nursing to run a test case for comparable worth in the Federal Conciliation and Arbitration Commission. Their claim failed, principally because they argued comparable worth in terms of 'worth to the employer' rather than make comparisons with suitable male occupations (Bennett 1993).

Turning to labour market setting, the human capital model of wage determination assumes that wages are determined in a competitive market equilibrium. In this model demand and supply imbalances are only temporary phenomenon as wages adjust to clear the market. Competitive market models assume many buyers (employers). At the other end of the continuum are monopoly or monopsony models where the employers (one in the case of a monopoly) collude to increase their bargaining strength and offer below market clearing wages. As England notes "The classic example of monopsony power is the labor market for nurses in small towns that only have one hospital" (1992, p.61). Nurses embody specialised skills for which close alternatives are few - thus further strengthening monopsony power in wage negotiations (Link and Landon 1975).

In Australia state governments employ approximately 70 per cent of nurses (see Table II) a further 16 to 20 per cent are employed in nursing homes and the remainder in community service, doctors surgeries and private (often small) hospitals (Nowak 2000). Funding for the hospital sector is shared between the state and federal governments and recent years have seen significant cuts in the size of health care budgets, placing pressure on hospital budgets and their capacity to fund salary adjustments (ibid.). Funding of nursing homes is also highly dependent on federal government outlays. The private sector typically follows the lead of the public sector in the negotiation and determination of nurse wage outcomes.

On going recruitment difficulties, resulting in a reported nursing 'shortage' are a manifestation of such monopsonist labour markets. In Australia the nursing shortage is the product of a shortfall in qualified nurses supplying their labour. Of all professionally qualified females, nurses in Australia exhibit the highest rate of non-participation in the labour market. Of the remainder a substantial proportion of qualified nurses ( 30 per cent in the case of degree qualified nurses) were employed outside the Health Industry (Birch 1999). A 'true' shortage carries with it the connotation that " ... 'reasonable' recruitment efforts have been made, and 'reasonable' wages and training prospects offered ..." (Green, Machin and Wilkinson 1998).

In the US there is mixed support for the monopsony model explanation of nursing wages. Booton and Lane (1985), for example, suggests that oligopsonistic market structures are present and have contributed to low rates of return on nursing degree credentials. Hirsch and Schumacher (Hirsch and Schumacher 1995) cast doubt on the monopsony hypothesis. In 
support of their position they find, amongst other things, little difference in the wages growth of RNs and other female control groups.

The Australian experience is, however, likely to differ from the US. As previously indicated, more than 70 per cent of RNs are employed in the government sector and hospital administrators have to work within tight budget constraints. Consistent with a monopsony model interpretation of the earnings gap the results show that the experience-earnings profiles of nurses are flatter than equivalent profiles for other groups. It is a pattern consistent with a managerial practice of discounting previous experience when RNs exit and subsequently reenter the workforce (Nowak 2000).

\section{CONCLUSION}

There is currently a perception amongst teenagers and junior RNs that nursing is a poorly remunerated occupation. Using data from the 1991 Australian Census this study empirically examined this proposition and found that after adjusting for differences in human capital endowments and other characteristics such as sex and sector of employment such perceptions were not unfounded. When compared to Health and Business Professionals, RNs earn 27.1 and 18.7 per cent, less, respectively. Overall it is apparent that human capital theory is not able to explain why nurses are so poorly paid. Differences in the earnings of nurses and other highly feminised professionals are manifestations of the historical undervaluation of women's work. Monopsonistic/Oligopsonistic market structures may be exacerbating the problem although an alternative argument suggests that the depressed earnings of hospital workers may not be so much a reflection of monopsony based power, but rather a constraint imposed by budgeting pressures and a desire not to disrupt customary wage relativities for fear of invoking invidious comparisons and resultant industrial unrest (Krall 1995).

From a policy perspective the results suggest the need for a program of research investigating nursing remuneration and the reality of monopsony power in Australia. Unionionisation is one potential offset to monopsonist/oligopsonist power. The moderating influences of unions must, therefore, also be examined in any study of nursing wages. A further program of research should examine the nurse labour supply elasticities with respect to RN wages. Research from the US suggests that wage increases would only have a modest effect on nurse labour supply (Link 1992; Ahlburg and Mahoney 1996). The Australian situation may be different.

\footnotetext{
10 RNs at the re-entry stage in Australia are typically faced with the prospect of 'starting over' each time they leave the workforce. Data on nursing levels for a sample of nurses in Western Australia show that in 1994 54 per cent of all RNs were Level 1 nurses, yet over 70 per cent of these Level 1 nurses were aged 35 or more and thus well into their ' (Nowak 2000, p.14)

11 Teachers have been subjected to similar influences (undervaluation and monopsony power), thus possibly explaining why there is no significant difference in the earnings of nurses and teachers, ceteris paribus.
} 


\section{REFERENCES}

Ahlburg, D.A. and C.B. Mahoney (1996), "The Effect of Wages on the Retention of Nurses" Canadian Journal of Economics 29(0, Sp. Iss., Part 1, April): S126-S129.

Bennett, L. (1993), "Equal Pay and Comparable Worth: Doctrine and Practice in the Commission" in B. Dabscheck, G. Griffin and J. Teicher (eds). Contemporary Australian Industrial Relations, Melbourne, Longman Cheshire: 419-432.

Birch, E. (1999), "The Rate of Return to Education: A Study of Nursing Credentials" Unpublished Honours Thesis, Department of Economics, Curtin University of Technology.

BIZTRAC (1998), "Junior Registered Nurses Labour Force Survey", Research Report prepared for the Health Department of WA by BIZTRAC, Faculty of Business and Public Management, Edith Cowan University, November.

Blinder, A. (1973), "Wage Discrimination: Reduced Form and Structural Estimates." Journal of Human Resources 8(4): 436-455.

Blinder, A. (1976), "On Dogmatism in Human Capital Theory", Journal of Human Resources 11(1): 8-22.

Booton, L.A. and J.I. Lane (1985), "Hospital Market Structure and the Return to Nursing Education.” Journal of Human Resources 20(2): 184-196.

England, P. (1992), Comparable Worth: Theories and Evidence, New York, Aldine De Gruyter.

Green, F., S. Machin and D. Wilkinson (1998), "The Meaning and Determinants of Skills Shortages." Oxford Bulletin of Economics and Statistics 60(2): 165-187.

Gregory, R.G. and A. Daly (1990), "Can Economic Theory Explain Why Australian Women Are So Well Paid Relative To Their US Counterparts?", Australian National University, Centre for Economic Policy Research, Discussion Paper No. 226.

Halvorsen, R. and R. Palmquist (1980), "The Interpretation of Dummy Variables in Semilogarithmic Equations." American Economic Review 70(3): 474-475.

Hearn, G. and A. Sheahan (1998), "Research to Assist the Development of a Camp gain to Promote Nursing as a Career", Research Report prepared for the Health Department of WA, Donovan Research.

Hirsch, B.T. and E.J. Schumacher (1995), "Monopsony Power and Relative Wages in the Labor Market for Nurses" Journal of Health Economics 14(4, October): 443-476.

Krall, L. (1995), "The rise and fall of customary wage differentials among nursing personnel in US hospitals: 1956-1985" Cambridge Journal of Economics 19: 405-419.

Lawler, J., M. Ahern, A. Stanley and S. West (1997), "Who Wants to be a Nurse?", Research Report Prepared for the Health Department of NSW by the Sydney Nursing Research Centre, The University of Sydney.

Link, C.R. (1992), "Labor Supply Behavior of Registered Nurse: Female Labor Supply in the Future?" in R. Ehrenberg (ed.) Research in Labor Economics Greenwich, JAI Press. 13: $287-320$.

Link, C.R. and J.H. Landon (1975), "Monopsony and Union Power in the Market for Nurses." Southern Economic Journal 41(4, April): 649-659.

Miller, P.W. and P. Volker (1987), "The Youth Labour Market in Australia", Economic Record, 63(182): 203-219.

Mincer, J. and S. Polacheck (1974), "Family Investments in Human Capital: Earnings of Women." Journal of Political Economy 32(2, Part II): S76-S108. 
Nowak, M.J. (2000), "The Nursing Labour Market in Western Australia: The Story of a Complex Micro-Labour Market in a Deregulating Environment" Women's Economic Policy Analysis Unit, Curtin University of Technology, Discussion Paper No. 00-1.

Oaxaca, R. (1973), "Male-Female Wage Differentials in Urban Labor Markets", International Economic Review, 14(3): 693-709.

Polachek, S. (1975), "Differences in Expected Post-School Investment as a Determinant of Market Wage Differentials." International Economic Review 16(2): 451-470.

Polachek, S. (1981), "Occupational Self-Selection: A Human Capital Approach to Differences in Occupational Structure." Review of Economics and Statistics 63(1): 6069.

Schumacher, E.J. and B.T. Hirsch (1997), "Compensating Differentials and Unmeasured Ability in the Labor Market for Nurses: Why Do Hospitals Pay More?" Industrial and Labor Relations Review 50(4, July): 557-579.

White, H. (1980), “A Heteroskedasticity Consistent Covariance Matrix Estimator and a Direct Test of Heteroskedasticity." Econometrica 48(4): 817-383.

Wooden, M. (1999), "Gender Pay Equity and Comparable Worth in Australia: A Reassessment." Australian Economic Review 32(2): 157-171. 


\section{APPENDIX A: DEFINITION OF VARIABLES}

Age: in the 1991 Census HSF the age information was coded on a continuous basis from age 0 through to 24 . From 25 to $85+$ the ages were grouped into bands of interval length 5 . The mid-point of each band was used to construct a continuous measure of age.

Birthplace: two controls for migrant birthplace were used: es $b=1$ for migrants born in an English speaking country; nes $b=1$ for migrants born in a non-English speaking country. Persons born in Australia formed the omitted category.

Dependants: a dummy variable controlling for the presence of dependant children (child) was created from information provided on the family type (FMTF) in the HSF.

Experience: a measure of potential labour market experience was computed as exp=(age of individual)-(years of schooling)-5. See information below on how the years of schooling variable was defined.

Geographic location: in the HSF information on geographic location was grouped into 20 categories. The variable metro is equal to 1 if the person resided in either: Inner Sydney; Sutherland and Liverpool; Outer South West New South Wales; Lower North New South Wales; Hunter and Illawarra; Western Outer Melbourne; Central Melbourne; East Outer Melbourne; Brisbane; Adelaide or Perth. (In the 1991 HSF Tasmania and the Australian Capital Territory were grouped together).

Highest Level of Education. In the HSF the education information was grouped as follows: (1) Higher Degree; (2) Post-Graduate Diploma; (3) Bachelor Degree; (4) Undergraduate Diploma; (5) Associate Diploma; (6) Skilled Vocational; (7) Basic Vocational; (8) Level of attainment inadequately described; (9) Level of attainment not stated; (10) not applicable. In this study the groups were reclassified as follows: degree $=(1)$, (2) or (3), and diploma (4). Groups (5), (6) and (7) formed the omitted category. Persons in the other groups were excluded from the sample.

Hours and Overtime: the relevant question was: "In the main job held last week, how many hours did the person work? Subtract any time of; add any overtime or extra time worked". The responses were grouped as follows: (1) none; (2) 1-14; (3) 15-24; (4) 25-34; (5) 35-39; (6) 40; (7) 41-48; (8) 49+. A full-time worker was defined as someone working $35+$ hours per week. A dummy variable to capture overtime work (otime) (41 or more hours per week) was also created.

Income: the income data in the Census measures income from all sources. Responses were coded into 16 groups. The mid point of each band was used to construct a continuous measure of income. The open-ended upper limit was given a value of 1.5 times the lower threshold level. Dividing annual income by 52 derived weekly earnings. The dependent variable throughout this paper is $\ln Y$, the natural logarithm of weekly earnings.

Marital Status: using the variable (MSTP) in the HSF two dummy variables were computed; married=1 for those who were married; $w s d=1$ for individuals who were either widowed, separated or divorced at the time of the Census. Individuals who had never married formed the omitted category.

Occupation: The five occupational groups were coded as follows. On the basis of data in the HSF, Health Diagnosis and Treatment Practitioners (HSF=10), School Teachers (HSF=24); Business Professionals (HSF=27) RNs (HSF=34); and Police $(H S F=35)$.

Years of Schooling: The 1991 HSF provided information on age on leaving school (ALS). Qualifications were used to estimate additional years of schooling or years to qualify (YTQ) as follows: Higher Degree=7; PostGraduate Diploma=4; Bachelor Degree=3; Undergraduate Diploma=3; Associate Diploma=2; Skilled Vocational certificate $=2$; Basic Vocational Certificate $=1$; Certificate - other level $=1$. Years of schooling (YOS) was thus defined as YOS=ALS+YTQ-5.

Sector of Employment: the control variable govt was defined as govt $=1$ for persons employed in either the Commonwealth Government, the State/Territory Government or Local Government. 